\title{
A useful method of using the healing abutments for interocclusal records in implant overdenture: a case report
}

\author{
Hyunsuk Choi ${ }^{1}$, Sohee Kang ${ }^{2}$ \\ ${ }^{1}$ Department of Dentistry and Prosthodontics, Daegu Catholic University School of Medicine, Daegu, Korea \\ ${ }^{2}$ Department of Dentistry, Yeungnam University College of Medicine, Daegu, Korea
}

To determine the vertical dimension and centric relation during the construction of implant overdentures, the record base and wax rim may need to be adjusted. The conventional method has several drawbacks, as it requires repeated tightening and loosening of the impression coping. Here, we report a useful and novel method for interocclusal records using the healing abutments in implant overdentures. Our case demonstrates that this method is easier and simpler and prevents gingival collapse.

Keywords: Centric relation; Healing abutment; Overlay denture; Record base; Vertical dimension

\section{Introduction}

Determining the vertical dimension and centric relation during the construction of implant overdentures requires the fabrication of a record base and wax rim on the master cast. For this procedure, impression coping or other attachments are used to ensure the stability of the record base.

Conventionally, the record base and wax rim are fabricated on the impression coping connected with the laboratory analog embedded in the master cast. However, in the clinical setting, this conventional method is time-consuming and inconvenient. Repeated tightening and loosening of the impression coping to adjust the occlusal rim can lead to gingival irritation. Moreover, in the case of multiple implants, only a few implants are used in connection with impression copings, and the unused implants remain connected to the healing abutments. In such a situation, soft tissue collapse may occur in the peri-implant areas during wax rim adjustments.

This article presents a useful method for interocclusal records using healing abutments in implant overdentures. The proposed technique is faster, simpler, and more convenient than the conventional method.

\section{Case}

Ethical statements: This study was approved by the Institutional Review Board (IRB) of the Daegu Catholic University Medical Center (IRB No: CR-21-165). Written informed consent was obtained for the publication of this case report and accompanying images.

A 65-year-old woman presented with a desire to have new dentures. The patient was partially edentulous in the maxilla and completely edentulous in the mandible. As a treatment plan, maxillary removable partial denture and mandibular implant overdenture were planned.

Two right implants with a diameter of $3.3 \mathrm{~mm}$ and a length of $11.5 \mathrm{~mm}$ and two left implants with a diameter of $4.0 \mathrm{~mm}$ and a

Received: August 19, 2021 • Revised: October 19, 2021 • Accepted: October 21, 2021

Corresponding author: Sohee Kang, DDS, PhD

Department of Dentistry, Yeungnam University College of Medicine, 170 Hyeonchung-ro, Nam-gu, Daegu 42415, Korea

Tel: +82-53-620-3282 • Fax: +82-53-629-1772•E-mail: kangsh@yu.ac.kr 


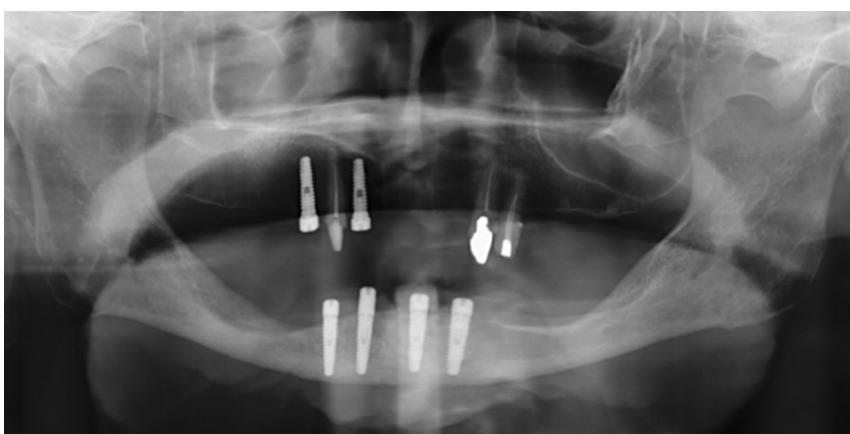

Fig. 1. Panoramic radiograph shows the placement of four implants in the mandible.

length of $11.5 \mathrm{~mm}$ were placed in the mandible (Fig. 1). The implants used in this study were external hex implants (ExFeel; Megagen, Daegu, Korea) [1]. After 4 months of healing, a mandibular pick-up implant impression was obtained using an individual tray fabricated on the study cast with minimal relief based on the dynamic impression concept [1].

Mini-sized healing abutments were selected for the two implants on the right and regular-sized healing abutments were selected for the two implants on the left. All healing abutments were placed $\geq 2 \mathrm{~mm}$ above the gingival level. Subsequently, each healing abutment was tightened using a torque of $20 \mathrm{~N} \cdot \mathrm{cm}$ applied with an auto torque driver (Meg-Torq, Megagen) on the laboratory analog (Megagen Lab Analog, Megagen). After blocking the gross tissue undercuts in the residual ridge areas with wax and providing minimal relief at the implant gingival sulcus around the healing abutments on the master cast, the record base was fabricated with a standard record base material (Ostron 100; GC Corp., Tokyo, Japan). After self-curing, the labial half of the abutment-engaged record base was trimmed to evaluate the fit between the record base and healing abutments (Fig. 2). The wax rim was fabricated on the record base using Boucher's method [2].

After autoclaving, each healing abutment was tightened in the same position as the oral implants (Fig. 3). The vertical dimension and centric relation were determined using the conventional method in the same manner as for complete dentures (Fig. 4) [2].

The correct fitness of the healing abutment and record base was assessed in the oral cavity and compared to that on the master cast. To determine the vertical dimension and interocclusal records, the record base and wax rim were easily and conveniently adjusted without tightening or loosening the impression copings [3].

Based on the interocclusal record, the prosthetic process was then performed, and the maxillary removable partial denture and mandibular overdenture were delivered to the patient.

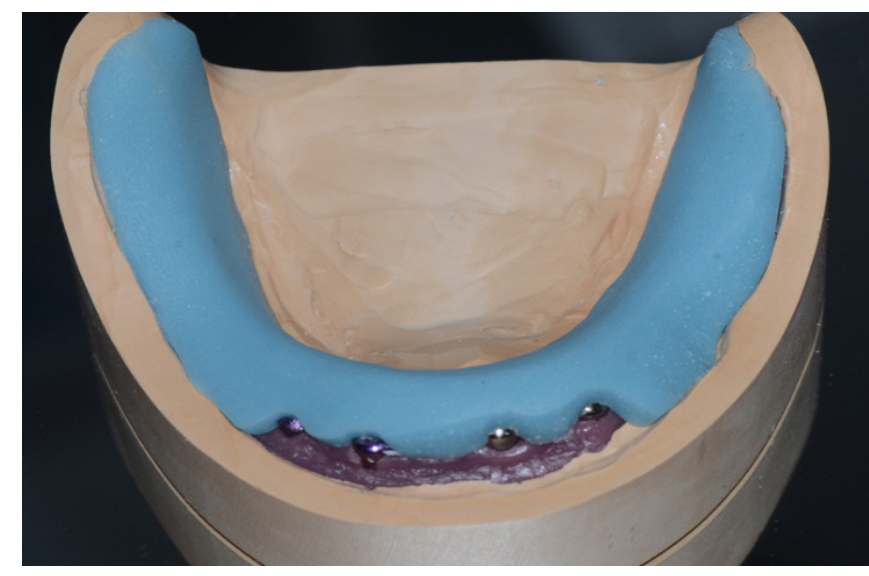

Fig. 2. Fabrication of the record base on the master cast with the healing abutments connected.

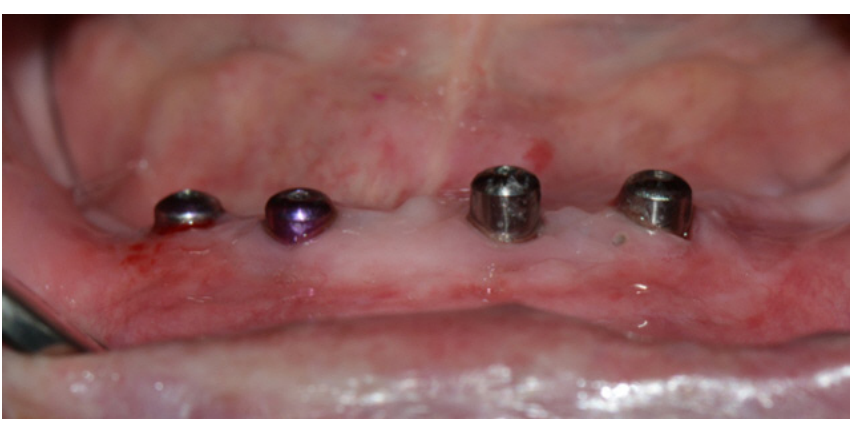

Fig. 3. Placement of the healing abutments in the oral cavity.

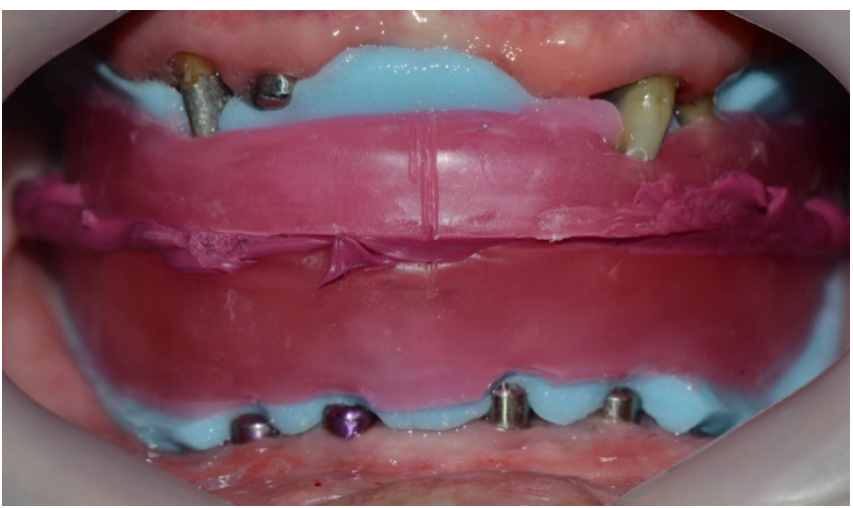

Fig. 4. Determination of the vertical dimension and centric relation. The artificial teeth of the denture are arranged at the position determined in this process.

\section{Discussion}

In this case report, we describe an alternative method for obtaining interocclusal records from a record base using the healing abutments in an implant overdenture. The record base was fabricated 
on the master cast, where the healing abutments were connected to laboratory analogs. In the clinical setting, the healing abutments used in the master cast are connected to the patient's mouth. Therefore, the record base and wax rim can be easily detached without the risk of gingival collapse in the peri-implant areas during the tightening or loosening of the impression copings to adjust the wax rim. Furthermore, the accuracy of denture impressions can be assessed by evaluating the fit between the healing abutments and record base, as the record base will not be correctly fitted if the pick-up impression is incorrect. In clinical situations, this method is especially suitable for external hex implants because abutment sinking may occasionally occur in internal, but not external hex implants [4].

To obtain the interocclusal record of the implant overdenture, healing abutments, which have many advantages compared to conventional methods, were used, and satisfactory results were obtained.

\section{Notes}

\section{Conflicts of interest}

No potential conflict of interest relevant to this article was reported.

\section{Funding}

None.

\section{Author contributions}

Conceptualization, Formal analysis: HC, SK; Data curation, Methodology, Visualization, Investigation: HC; Supervision, Validation: SK; Writing-original draft: HC; Writing-review \& editing: HC, SK.

\section{ORCID}

Hyunsuk Choi, https://orcid.org/0000-0002-0381-3870

Sohee Kang, https://orcid.org/0000-0002-3667-1952

\section{References}

1. Lee BK, Park SH, Lee CH, Cho JH. Implant overdenture impressions using a dynamic impression concept. J Adv Prosthodont 2014;6:66-9.

2. Anderson JD, Zarb G. The dentures' polished surfaces, recording jaw relations, and their transfer to an articulator. In: Zarb G, Hobkirk JA, Eckert SE, Jacob RF, editors. Prosthodontic treatment for edentulous patients: complete dentures and implantsupported prostheses. 13th ed. St. Louis: Elsevier Mosby; 2013. p. $180-203$.

3. Park JH, Cho JH. A clinical report of hybrid telescopic double crown denture with friction pin in a failed double crown denture case. J Korean Acad Prosthodont 2021;59:201-9.

4. Shin HM, Huh JB, Yun MJ, Jeon YC, Chang BM, Jeong CM. Influence of the implant-abutment connection design and diameter on the screw joint stability. J Adv Prosthodont 2014;6:12632. 